\title{
A Specification for an Autonomous Crop Production Mechanization System
}

\author{
B.S. Blackmore ${ }^{1}$, H.W. Griepentrog ${ }^{2}$, S. Fountas ${ }^{1}$, T.A. Gemtos ${ }^{1}$ \\ 1) University of Thessaly, Department of Agriculture, Crop Production and Rural Environment, \\ Farm Mechanization Lab, Fytoko str., 38446 N. Ionia Magnisias, Greece. \\ 2) University of Copenhagen, Faculty of Life Sciences (KVL), Taastrup Campus, Taastrup, \\ Denmark
}

Corresponding author: blackmore@uth.gr ; simon@unibots.com

\begin{abstract}
This paper describes the specification of requirements and the functionality, of a novel agricultural mechanisation system based on small smart machines. It separates the current mechanisation methods from the original plant requirements and in doing so allows a new specification to develop based on agronomic, economic and environmental needs that can lead to a more sustainable production system. Three main groups of field operations have been identified; Crop establishment, Plant care and Selective harvesting. Each process and operation brings its own challenges and opportunities. The resulting framework should give the basis for mechanisation well into the $21^{\text {st }}$ century.
\end{abstract}

Keywords: Agricultural robots, machinery, crop establishment, selective harvesting, crop care.

\section{INTRODUCTION}

Developed agriculture uses many types of machinery to enhance production. Most of these machines are adaptations from older designs and some have not changed much for centuries. During the industrial revolution, new energy sources became available that allowed machines to replace hand labour. The interaction between machines and operators has hardly changed since that time. The human operator uses their intelligence to operate a mechanical tractor and implement. Automatic sub systems are now becoming common place and new driver-assist technologies such as straight line assisted steering are now being commercialised. It would seem that it is inevitable that machines will become smarter in the future, to the point where they are able to carry out the tasks autonomously.

Autonomous vehicles have been widely used in industrial production facilities and warehouses, where a controlled environment can be guaranteed. In agriculture, research into driverless vehicles has always been a dream and basic research started out in the early 1960's. These projects mainly involved automatic steered tractors (a review can be seen at Wilson (2000)).

B.S. Blackmore, H. Griepentrog, S. Fountas, and T. Gemtos. "A Specification for an Autonomous Crop Production Mechanization System”. Agricultural Engineering International: the CIGR Ejournal. Manuscript PM 06 032. Vol. IX. September, 2007. 
Furthermore, Hollingum (1999) reviewed the agricultural robotic developments around the world and Kondo and Ting (1998) elaborated on robotics for bio production systems, including open fields. In recent years the development of autonomous vehicles in agriculture has experienced an increased interest. There are a number of prototypes that have been reported in horticultural crops, such as oranges (Hannan and Burks, 2004), apples (Kataoka, et al., 2001), strawberries (Kondo et al., 2005), tomatoes (Chi and Ling, 2004). For field crops there are also a number of prototypes, such as the Demeter system for automated harvesting equipped with a video camera and GPS for navigation (Pilarski et al., 2002), the autonomous Christmas tree weeder (Have et al., 2002) and the API platform for patch spraying (Bak and Jacobsen, 2003).

This paper sets out a specification of requirements for such a system and attempts to break the linkage between how the tasks are carried out at present and how they could be carried out to service the fundamental plant needs. In doing so, a complete new integrated autonomous mechanisation system starts to develop.

\subsection{Current Mechanisation Trends}

Most new machines brought to the market are bigger than the previous model (reference?). When discussing this issue with equipment manufactures, this trend is likely to continue into the future. The driving force for this growth would seem to be to take advantage of the economies of scale that larger machines bring with them. This is easily demonstrated if the cost of the operator is taken into account. As most operators are paid by the hour, a larger machine that can increase the work rate over a smaller one can have a significant economic advantage.

This size increase does not only bring benefits. Large machines are only viable when working in large fields as turning, positioning and transport are all non productive activities. Although many farms have removed field boundaries to take advantage of the larger machines, many smaller farms cannot follow suite due to environmental concerns and suffer economically because of it.

As this equipment becomes larger, it also becomes very capital intensive with new tractors and combines becoming prohibitively expensive for the small and medium sized farm. Reliability also becomes an issue as all processes are carried out in series. If one part of the mechanisation system breaks down then all field operations stop.

\subsection{Phytotechnology}

An alternative approach would be to use available information technologies to automate these processes to the point where they do not need a human operator. By removing the person from the immediate control of the system, it offers new opportunities but also creates new problems. Once the person is outside the control loop, then the economies of scale that applied to the larger

B.S. Blackmore, H. Griepentrog, S. Fountas, and T. Gemtos. "A Specification for an Autonomous Crop Production Mechanization System”. Agricultural Engineering International: the CIGR Ejournal. Manuscript PM 06 032. Vol. IX. September, 2007. 
manned tractors does not apply and alternative smaller smarter systems can be developed. Work rates (per day) can be kept high by working longer hours and using multiple machines.

Given that the scale of treatment areas have been reduced over the last few years, due to the adoption of Precision Farming practices, from farm scale down to sub field scale, this reduction could continue down to individual plant scale treatments. This approach then becomes close to what people do when caring for plants in their own garden but is not usually realistic in a commercial environment. To make this approach practically viable, the machines must have enough intelligence embedded within them to carry out these tasks without anyone present. This concept called Phytotechnology was first described by Shibusawa. (Shibusawa, 1996)

By taking a systems approach to designing Phytotechnology, consideration can be given to a system in terms of its action, interactions and implications. The result should be a new mechanisation system that collectively deals with the crop's agronomic needs in a better way than is done now. Most people define agronomic processes in terms of how they are currently carried out and a break from this mentality, or paradigm shift, is needed to define the processes in terms of the fundamental plant needs. When the plant requirements are defined independently of the machine that carries out the corresponding operations, this improved specification can be used in conjunction with mechatronic principles to help design smarter and more efficient machines.

\subsection{Traditional Concepts}

A number of traditional concepts of plant production are now being revisited and reconsidered in the light of developing smarter machines.

During primary cultivation, the whole topsoil of a field is inverted with a plough to create a suitable seed bed. This is a generic operation that suits many circumstances but it uses a lot of energy. If this is turned around to consider the actual seed requirements, other options may become clearer. The seed requires contact with soil moisture to allow uptake of water and nutrients; it requires a structure that can hold the plant upright but also allow the roots to develop and the shoots to grow. If this same seed environment can be achieved by only mixing the soil within a few centimetres of the actual seed then the rest of the soil does not need to be disturbed as it can be well conditioned by natural soil flora and fauna.

Another traditional concept is to grow crops in rows. It would seem that the only explanation as to why this is done is that it requires the simplest type of machines. Seeds are placed relatively densely along each row and we rely on crop plasticity to fill out the canopy. The problem is that in principle, each plant requires equal access to light, air, water and nutrients, which are often spatially related. Intra crop competition can be reduced by giving a more even or equal spacing,

B.S. Blackmore, H. Griepentrog, S. Fountas, and T. Gemtos. "A Specification for an Autonomous Crop Production Mechanization System”. Agricultural Engineering International: the CIGR Ejournal. Manuscript PM 06 032. Vol. IX. September, 2007. 
which in turn requires more accurate placement of seed by placing seed in a more uniform pattern

If the location of each seed is known and the position of each emerged crop plant is estimated, we can identify each plant by its spatial location. Improved information about plant characteristics allows improved management and decision making and allows a number of improved, more targeted operations that can improve the overall efficiency of crop growing to be carried out.

The traditional configuration of tractors supplying the tractive power coupled with human intelligence and using trailed or mounted equipment can be reconsidered in light of smarter machines. As the smarter implements are obviously more task specific it may be better to have them self propelled or make the implement take control of the tractor. In this way, the intelligence needed to carry out a specific task can be embedded within the appropriate machine, while the tractive force (the tractor) could be generic.

\subsection{Machine Size}

At present, machine efficiency (in terms of work rates) is being improved by increasing machine size and improved efficacy can be achieved by adding driver assisting technologies and limited machine intelligence such as auto steer and variable rate applications. This is approaching a local maxima (1) shown in Figure 1.

B.S. Blackmore, H. Griepentrog, S. Fountas, and T. Gemtos. "A Specification for an Autonomous Crop Production Mechanization System”. Agricultural Engineering International: the CIGR Ejournal. Manuscript PM 06 032. Vol. IX. September, 2007. 


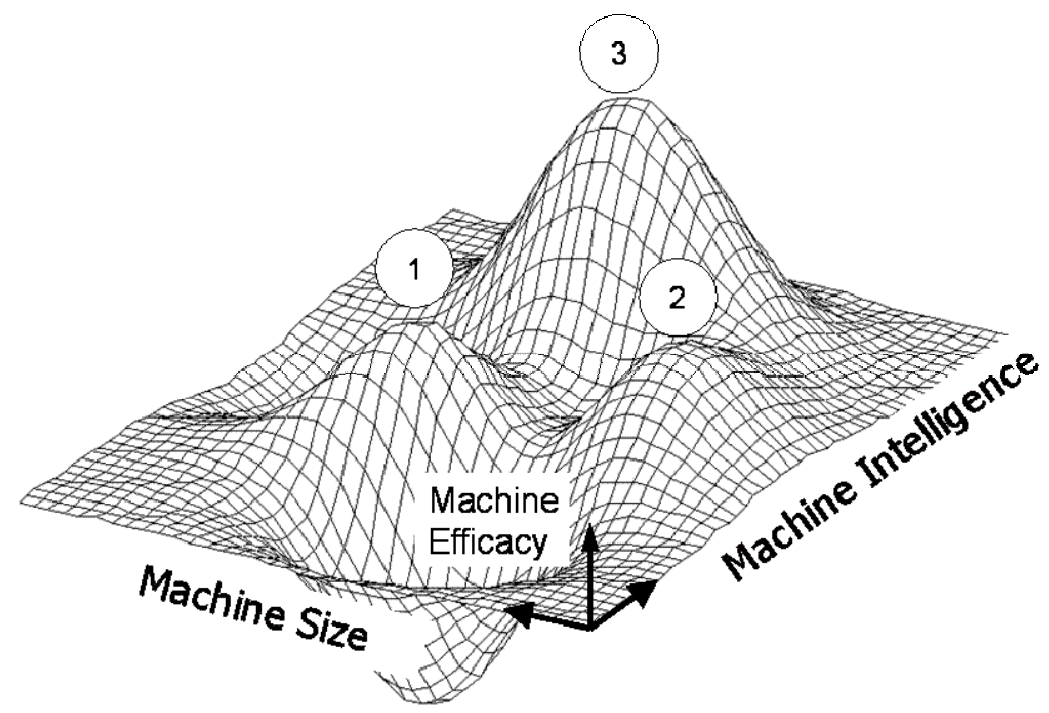

Figure 1. Hypotnesıseu reıatıonsnıp detween macnıne sıze, macnıne ınteıngence and resulting efficacy.

If the driver is removed and the machine is made a lot smaller, as are the current small research robots, then efficacy can be about the same (local maxima 2). If however, small machines are endowed with enough intelligence to allow them to work autonomously, then a greatly increased efficacy is envisaged (local maxima 3). Note that the present incremental change appears to be peaking at (1) and (3) cannot be reached by incremental changes alone as the removal of the operator requires new systems. This is where the paradigm shift is needed to allow the development of new machines and systems that will move onto the next level of efficacy (3).

\section{CONCEPTUAL SYSTEM REQUIREMENTS}

The following characteristics have been identified as useful to enhance the conceptual system. These have come from both idealised situations and from existing research.

\subsection{Light Weight}

All agricultural machines should be as light as possible as this implies reduced soil compaction. Chamen et al. (1994) has identified that a 70\% energy saving can be achieved in cultivation by moving from traditional trafficked systems (255 MJ/ha) to a non-trafficked system (79 MJ/ha). This was for shallow ploughing and did not include any deep loosening. From this it is estimated that $80-90 \%$ of the energy going into traditional cultivation is there to repair the damage done by

B.S. Blackmore, H. Griepentrog, S. Fountas, and T. Gemtos. "A Specification for an Autonomous Crop Production Mechanization System”. Agricultural Engineering International: the CIGR Ejournal. Manuscript PM 06 032. Vol. IX. September, 2007. 
large vehicles. As the autonomous vehicles are inherently light, it is possible to have lower energy inputs and induce less soil compaction.

\subsection{Small Autonomous Machines}

The first autonomous vehicles should be small for a number of reasons. Firstly, when a system failure occurs it is less likely that the resulting random action will be property or life threatening. Secondly, as there is no longer an operator on board then there is no need to carry that mass, nor the safety cab. Thirdly, the small machines could have the same work rates per day as manned ones if multiple machines were used for longer periods with the possibility of 24 hour operations. The smaller size and slower speeds also implies higher precision with the possibility to produce more self propelled implements that are designed for a specific purpose such as physical weeding or crop scouting.

Multiple small machines are highly scaleable in that if higher work rates are needed then another machine could be purchased or borrowed. As these machines can be produced locally, then the investment can be made incrementally each year rather than on a large tractor every few years.

It is envisaged that these machines could be made from existing agricultural and automotive parts that are already in production, which will significantly reduce the price of production. A current (2006) student project at the University of Thessaly in Greece is designing and evaluating a 4WD/4WS crop scouting robot being constructed by a skilled rural blacksmith using easily available parts.

\subsection{Computational and Energetic Autonomy}

There are many levels of autonomy from automatic subsystems through to total autonomy, although the latter is very rare as some level of human intervention is usually required. Computational autonomy deals with the problem of how to program the machine to carry out its task independently, whereas the energetic autonomy concept deals with the energy systems required to power the robot from local energy sources. Although this has been trialled, the resulting work rates are very low (Ieropoulos et al., 2003; Kelly et al., 2000). Many researchers in mobile robotics focus on computational autonomy as this is seen as a major challenge. In outdoor environments the problem is even more difficult as the robot must deal with inherently complex biological variability of the surroundings.

B.S. Blackmore, H. Griepentrog, S. Fountas, and T. Gemtos. "A Specification for an Autonomous Crop Production Mechanization System”. Agricultural Engineering International: the CIGR Ejournal. Manuscript PM 06 032. Vol. IX. September, 2007. 


\subsection{Machine Intelligence}

It is instinctive, from a human perspective, to know what is meant by intelligence but what is found easy by humans is often difficult to achieve in a computer. Furthermore, intelligence is difficult to define and can only be compared to human intelligence. In fact, what is needed is not an intelligent machine but one that carries out a set of well defined tasks in a given context.

Another approach is to define the actions of the machines in terms of operations, tasks and behaviours. Many researchers working in robotics consider behaviour-based robotics to be the most appropriate way to develop truly autonomous vehicles (e.g Brooks, 1999; Na and Oh, 2003; Yavuz and Bradshaw, 2002). In this way, a definition of autonomous vehicle behaviour can be expressed as sensible long-term behaviour, unattended, in a semi-natural environment, while carrying out a useful task.

This sensible long-term behaviour is made up of a number of parts. Firstly, sensible behaviour needs to be defined, which at the moment is device independent. Alan Turing defined a simple test for artificial intelligence (Turing 1950), which essentially states that if a machine's behaviour is indistinguishable from a person then it must be intelligent. Currently, it is not possible to develop an intelligent machine but it can be made more intelligent than it is today by defining a set of behaviour modes that make it react in a sensible way, defined by people, to a predefined set of stimuli or triggers within known contexts in the form of an expert system. Secondly, it must be able to carry out its task over prolonged periods, unattended. When it needs to refuel or resupply logistics, it must be capable of returning to base and restocking. Thirdly, safety behaviours are important at a number of levels. The operational modes of the machine must make it safe to others as well as itself, but it must be capable of graceful degradation when sub-systems malfunction. Catastrophic failure must be avoided, so multiple levels of system redundancy must be designed into the vehicle. Fourthly, as the vehicle is interacting with the complex semi-natural environment such as horticulture, agriculture, parkland and forestry, it must use sophisticated sensing and control systems to be able to behave correctly in complex situations. Many projects in the past have found ways to simplify the environment to suit the vehicle, but the approach should now be to embed enough intelligence within the tractor to allow suitable emergent behaviour to work in an unmodified environment. (Blackmore et al., 2001; 2004a)

\subsection{External Behaviour}

The autonomous machines should be able to carry out a range of well defined field operations, such as seeding and weeding, which are made up from tasks that exhibit predefined behaviours. These external behaviours can be made up of a mixture of pre defined deterministic tasks and real-time reactive behaviours.

B.S. Blackmore, H. Griepentrog, S. Fountas, and T. Gemtos. "A Specification for an Autonomous Crop Production Mechanization System”. Agricultural Engineering International: the CIGR Ejournal. Manuscript PM 06 032. Vol. IX. September, 2007. 
Deterministic tasks are those concerted actions that can be planned before the operation starts (e.g. route plan). Deterministic tasks can be optimised in terms of best utilising existing resources based on the prior knowledge about the tractor and field conditions.

Reactive tasks are those actions that are carried out when uncertainty is encountered. These tasks react in real-time to local conditions that were not known before the operation started. Reactive tasks can be defined by their behaviour to certain classes of situations (e.g. stopping when approached, obstacle avoidance). The choice of appropriate reactive task is made by identifying a trigger and the context of the situation (Blackmore et al., 2004b).

\subsection{Communication}

Communication between the farm office and the vehicles is important to allow the manager the opportunity to know what the machines are doing at any point in time, as well as the machines being able to receive commands and record their status and completed tasks. When a partial systems failure occurs, warning messages can be sent via different medias to the manager. These messages could take the form of text messages to a mobile phone or update a display on the farm PC. It is envisaged that the current workings and status of the vehicles could be represented in the form of a mimic on the screen that will show the conditions of all of the main systems. Remote diagnostics from the supplier and online assistance could well help with problem solving and even pre-emptive servicing.

When multiple machines are used, three levels of interaction have been identified; Coordination, cooperation and collaboration.

Coordination of multiple vehicles can be carried out centrally. Each vehicle works independently and does not necessarily know about other vehicles but has their own task to carry out. An example would be where each vehicle would be carrying out different tasks in different fields.

Cooperation is where multiple vehicles are working in the same field and are aware of each other and what each other are doing. If three vehicles were carrying out the same task, such as mechanical weeding in the same field, then each vehicle should know which rows other vehicles are working in before they select a new row to start in as it would not make sense for two vehicles to come head-to-head in the same row. Real time communications between vehicles on a peer-to-peer basis would be needed.

Collaboration is where multiple vehicles could share the same task at the same time. An example would be for multiple vehicles to pull a large trailer that one vehicle could not pull on its own. This is a very difficult situation to manage effectively

B.S. Blackmore, H. Griepentrog, S. Fountas, and T. Gemtos. "A Specification for an Autonomous Crop Production Mechanization System”. Agricultural Engineering International: the CIGR Ejournal. Manuscript PM 06 032. Vol. IX. September, 2007. 


\subsection{Weather}

Most field operations are dependant to some degree on the weather. Cultivations cannot be carried out if the soil is too wet, spraying can only start when there is little wind, etc. The design of the autonomous machines should include the ability of having different levels of weather dependence and independence. Weather dependence would be where the autonomous sprayer could stop when conditions were too windy and wait until it could start again. This approach is unfeasible for a manned vehicle but simple for an autonomous one. Weather independence is where the design of the machine allows operations to be carried out regardless of the current weather conditions. One example would be where the machines were made so light that they would not cause significant soil compaction even when the soil was wet.

\subsection{Vehicle System Architecture}

Inherently complex and sophisticated system architecture is required to control the autonomous vehicles. A subsumption model can be used as some of the more primitive behaviours and processes are subsumed within higher collective ones (Brooks, 1986). Similarly, each of the main internal behaviours can be modelled by a process. In this way an object oriented systems architecture can be created that allows the complex behaviours to be modelled and keep the overall system manageable (Blackmore et al., 2002).

\subsection{Graceful Degradation}

Graceful degradation is the process where parts of the system fail but the overall system is capable of functioning even though with a reduced capability. This generally involves only part of the task being fulfilled, which is arguably better than a complete shut down. Functionality is gradually reduced as faults increase. Only systems with redundant sub systems can allow this type of internal behaviour.

Six levels of functionality have been identified: Nominal safe operation, Safe operation with warnings, Partial system shut down - mobile, Partial system shut down - immobile, Stopped still communicating, Dead or communications failure (Blackmore et al., 2001).

\subsection{Self-awareness}

Self awareness is the situation where the machine has the added functionality to know about its own processes and contexts. This can range from simple parameters such as fuel levels and engine temperatures, through to (ultimately) recognition of local proximity and objects. When a

B.S. Blackmore, H. Griepentrog, S. Fountas, and T. Gemtos. "A Specification for an Autonomous Crop Production Mechanization System”. Agricultural Engineering International: the CIGR Ejournal. Manuscript PM 06 032. Vol. IX. September, 2007. 
combination of factors occurs then appropriate action can follow. For example, if the vehicle was carrying out a weeding operation and fuel was getting low (trigger), it would be sensible to wait until it reached the end of the row (context) before going to refuel (a new operation).

\subsection{Management}

Although many sub tasks can be automated, the role of the manager is still paramount to economic success and prolonged sustainability. Various tools and techniques can be used to help support the decision making process and a detailed study of how managers make decisions has shown that most Precision Agriculture approaches have made the management too complex. Only when these approaches can be simplified will Precision Agriculture move into the mainstream farming culture. A start has been made by analysing what decisions are made and how they are made by carrying out a sophisticated decision analysis that has resulted in a better understanding of these processes (Fountas et al., 2006).

Real time modelling is the concept of using automatically gathered data from the growing crop to incrementally update and improve the predictions from continuously running growth models. As these models are running in real time they are more likely to help improve the real time decision made by the manager and may be able to indicate limiting factors in real time.

Many parts of this complexity can be embedded within suitable software to allow the manager to exercise higher level control over the farm operations and business. To do this business support software must have the ability to represent different levels of personal preferences such as attitudes to risk, consideration for the environment, compliance with laws, health and safety. Only then can the support of management decisions within such complex systems become realistic.

In this new system, there are many new alternative management opportunities as well. One possibility is to consider phased cropping. Instead of planting the entire crop at the same time and then having the problem of only small available time windows to carry out spraying, fertilising, harvesting, etc., planting would occur during timed intervals that would allow phased operations over time. This would significantly reduce the peak machinery work loads and lead to better machinery usage over longer periods of time which would be ideal for smaller autonomous machines.

There may be another advantage from phased cropping due to the reduced possibility of crop failure due to weather conditions. If the entire farm acreage is planted at the same time then the whole crop may be at risk from a weather event (e.g. drought, hail etc) at a critical time. If the crop was split into two or three phases then a single event will have less impact as no more than half the crop is at the same stage. Conversely, in a good year, the overall yield may not be

B.S. Blackmore, H. Griepentrog, S. Fountas, and T. Gemtos. "A Specification for an Autonomous Crop Production Mechanization System”. Agricultural Engineering International: the CIGR Ejournal. Manuscript PM 06 032. Vol. IX. September, 2007. 
reached when phased cropping is used but it does give the possibility to spread the risk over two or three phases.

The automated gathering of data for tracking and tracing can add value to produce as it can be tied in to a particular treatment regimes such as best management practice or organic farming.

\subsection{Economics}

The cost of manned operations compared to autonomous operations can be very high. As some of these operations are low skilled and repetitive they make an ideal situation for automation. Additional costs of computers are not that much but the cost of the sensors and RTK GPS are still quite high. Even so, significant savings can be made in a number of operations (Pedersen et al., 2006).

\subsection{Mechanisation Tasks}

Given that many agricultural operations could be carried out autonomously, it would appear that the crop production cycle could be reduced to three main stages: Establishment, crop care and (selective) harvesting. Each of the three sections will firstly address the concepts and be followed by practical considerations in the mechanisation part.

\section{CROP ESTABLISHMENT}

\subsection{Concepts for Establishment}

\subsubsection{Seedbed Preparation}

Ploughing is one of the most important primary cultivation processes and has been carried out since the start of civilization. It is effectively the inversion or mixing of topsoil to prepare a suitable seed bed. It also has the ability to bury surface crop residues and control weeds. A small robot utilising current technology does not have the energy density to sustain ploughing over a large area due to the high levels of energy needed to cut and invert the dense soil. Secondly, the draft force required to plough also needs relatively high weight to give traction. By considering what the plant, or in this case the seed actually needs, we can approach the problem in a different way. The seed requires contact with the soil moisture to allow uptake of water and nutrients, it

B.S. Blackmore, H. Griepentrog, S. Fountas, and T. Gemtos. "A Specification for an Autonomous Crop Production Mechanization System”. Agricultural Engineering International: the CIGR Ejournal. Manuscript PM 06 032. Vol. IX. September, 2007. 
requires stability to hold the growing plant and a structure that allows the roots to develop and the shoots to grow. A solution is two fold. Firstly, if we do not compact the soil in the first place there is less need for energy inputs for remedial loosening. Natural soil flora and fauna can be encouraged to manipulate the soil to give a good structure. This is one of the reasons to opt for smaller machines. Secondly, only the local environment of the seed needs to be conditioned before seed placement. By using micro tillage rather than macro tillage a lot less energy would be used for crop establishment. Add to this the ability to place nutrients in the correct proximity to the seed we can improve the early phase of establishment.

\subsubsection{Seed Mapping}

Seed mapping is the concept of passively recording the geospatial position of each seed as it goes into the ground. The seed coordinates, or seed map, can then be used to target subsequent plant based operations.

\subsubsection{Seed Placement}

At present, most seeds are planted at high densities within each crop row, whilst having relatively more space between the rows. In terms of agronomic principles, each plant should have equal access to spatial resources of air, light, ground moisture, etc. Ultra high precision seeding would allow the spatial variance of seed density to be changed according to local conditions while retaining equal resources for each plant. Depth of seed placement could also be adjusted according to soil moisture.

Alternative seeding patterns might be more efficient in this context. If suitable controls are fitted to the seeder to allow synchronisation between passes, then there is the possibility to plant seeds on a regular grid that could allow orthogonal inter-row weeding. Grid seeding patterns could also be made permanent, which would allow non productive areas within the crop to be untouched from year to year.

\subsubsection{Reseeding}

Reseeding is the concept of being able to identify where a seed was not planted, or that a crop plant has not emerged and that a machine can automatically place another seed in the same position. Given that germination rates are usually between 80 - 90 percent there is the possibility to increase production by 10 - 20 percent without any extra costs of inputs. This concept could be extended to transplanting a seedling instead of a seed if the surrounding plants are too far advanced. A reseeder would have the ability to insert individual seeds/plants without disturbing

B.S. Blackmore, H. Griepentrog, S. Fountas, and T. Gemtos. "A Specification for an Autonomous Crop Production Mechanization System”. Agricultural Engineering International: the CIGR Ejournal. Manuscript PM 06 032. Vol. IX. September, 2007. 
the surrounding crop. Conventional seeders can not be used as they create continuous slots in the soil.

\subsubsection{Stones}

An autonomous stone picking / grading machine could be developed using machine vision if there is sufficient contrast or colour differences between the stones and surrounding soil. Stones are inherently dense and will often deliver many tons per hectare which will lead to issues of moving such large masses from the field without causing compaction. This could be done during dry summer months if there is no crop cover.

\subsection{Mechanisation for Establishment}

\subsubsection{Micro Tillage / Conditioning}

As only a small volume of soil is needed to be cultivated there are a number of different methods that could be used. Rotary mechanical tillage on a vertical or horizontal axis could be used but this may displace soil away from where the seed will be placed. Conversely, this could also be beneficial when encountering stones or clods as these would also be pushed aside. A vertical punch mechanism could also be effective. Water-jetting or the injection of a hygroscopic polymer gel could be used to create a micro climate for the seed.

\subsubsection{Seed Mapping}

Seed mapping is relatively simple in practice as a tilt adjusted RTK GPS is fitted to the high precision seeder and infra red sensors mounted below the seed chute. As the seed drops, it cuts the infrared beam and triggers a data logger that records the indicated position and orientation of the seeder. A simple kinematic model can then calculate the actual seed position (Griepentrog et al., 2005a).

\subsubsection{Seed Placement}

Ultra high precision placement of seed is difficult from a moving machine. Even the most sophisticated commercial machines have problems with consistently separating individual seeds and will often damage the seeds as they pass through the metering mechanisms. Some mechanisms do ensure that each seed has zero ground velocity which is important to stop the seed bouncing after impact with the soil (Griepentrog et al., 2005b).

B.S. Blackmore, H. Griepentrog, S. Fountas, and T. Gemtos. "A Specification for an Autonomous Crop Production Mechanization System”. Agricultural Engineering International: the CIGR Ejournal. Manuscript PM 06 032. Vol. IX. September, 2007. 


\subsubsection{Reseeding}

A punch planter could be developed to fulfil this role, or alternatively adapt a paddy rice transplanter to deal with one seedling at a time. Prior conditioning could be used to pierce the soil and soften it ready for the seedling roots (see above).

\subsubsection{Residues}

As ploughing is used to also incorporate crop residues, this may be achieved by displacing residues away from the seed area or using a whole crop harvester so there are little residues to deal with. If no till policies are adopted then the soil weed seed bank will diminish over time and the viability of new seeds dropped on the surface are kept low

\section{CROP CARE}

\subsection{Concepts for Crop Care}

\subsubsection{Crop Scouting}

One of the important parts of good management is the ability to collect timely and accurate information about the growing crop. Quantified data has tended to be expensive and sampling costs can quickly out weigh the benefits of spatially variable management. (Godwin et al., 2001) Data collection would be less expensive and timelier if an automated system could remain within the crop canopy for continual monitoring that can be used for assessing crop status. This could be achieved by either embedding cheap wireless sensors at strategic positions within the crop, or placing more expensive sensors onto a moving platform. Prior knowledge about the soil and crop would help to adapt the sampling strategy away from a grid pattern to a more targeted approach that could better utilise resources. Management zones can be delineated to represent homogenous areas of treatment that could be different for each factor (Godwin et al., 2001)). Particular soil characteristics could be moisture holding capacity (often correlated to soil type), topography (even micro topography is important as water moves down hill), organic matter (effect on nutrients) etc. Crop characteristics would include Leaf Area Index, crop height (giving growth rates), growth stage, biomass, senescence, etc. Crop nutrient status is difficult to assess in the early stages and assessing it independently from moisture stress become very complex (Christensen et al., 2005).

Preparation of maps or crop scouting prior to treatments is another part of management information that can be carried out by autonomous machines. There are many sensing techniques that that can ascertain crop and soil health. Many of them could be used now, apart from the fact

B.S. Blackmore, H. Griepentrog, S. Fountas, and T. Gemtos. "A Specification for an Autonomous Crop Production Mechanization System”. Agricultural Engineering International: the CIGR Ejournal. Manuscript PM 06 032. Vol. IX. September, 2007. 
that they take a long time to process the data. Examples are multi-spectral response from the plant canopy that can indicate stress (whatever the cause) and chlorophyll content is associated with crop vigour. Carbon dioxide $\left(\mathrm{CO}_{2}\right)$ has been associated with soil health, Ethylene can be associated with pest attack and conductivity has been correlated with soil moisture. (Waine, 1999; Waine et al., 2000) Soil nitrates, organic matter, Charged-ion Exchange Capacity (CEC), $\mathrm{pH}$ and soil moisture have been measured at different depths using Near Infra-Red (NIR) reflectance with a soil photo spectrometer (Shibusawa et al., 2000). Ion Selective Field Effect Transistors (ISFETs) can be modified to be sensitive to nitrates, $\mathrm{pH}$ and other factors from soil solution (Birrell and Hummel, 2001).

With the advent of biosensors, a whole new set of opportunities will become available to monitor growing crops for pest and disease attack (Tothill, 2001). As the autonomous machine could patrol the fields continually looking for these threats, real-time alerts could be sent to the manager whenever certain conditions were encountered. These could take the form of noting actual pest or disease attack, through to monitoring environmental conditions where they are likely to occur or that the risk of attack is significantly high through real time modelling.

\subsubsection{Weed Mapping}

Weed mapping is the process of recording the position, density (biomass) and preferably species of different weeds using machine vision. One method is to record the increased leaf area found in weedy areas as weeds are patchy and the crops are planted in rows (Pedersen, 2001). Another more accurate method is to use active shape recognition, originally developed to recognise human faces, to classify weed species by the shape of their outline (Søgaard and Heisel, 2002). Current research has shown that up to 19 species can be recognised in this way. Colour segmentation has also shown to be useful in weed recognition (Tang et al., 2000). The final result is a weed map that can be further interpreted into a treatment map.

\subsubsection{Physical Weeding Methods}

There are many physical methods that can kill, remove or retard unwanted plants without using chemicals (Nørremark and Griepentrog, 2004). These can range from total removal down to simple retardation. A classic example would be to promote the wilting of the weed plants by breaking the soil and root interface by tilling the soil within the root zone.

There are three main areas within the crop environment that require different types of treatment: The inter-row area (the space between the crop rows), the intra-row area (the space between the plants within the row), and the close-to-crop area that is within the leaf and root envelope. The closer to the crop that a machine should operate, increased care and accuracy is needed so as not to damage the plant tissue.

B.S. Blackmore, H. Griepentrog, S. Fountas, and T. Gemtos. "A Specification for an Autonomous Crop Production Mechanization System”. Agricultural Engineering International: the CIGR Ejournal. Manuscript PM 06 032. Vol. IX. September, 2007. 
The inter-row area is relatively easy to keep free of weeds as it is an open strip in line with the direction of travel. The intra-row area is more difficult to manage as it is an intermittent space delineated by irregular spacing of crop plants. The close-to-crop area should not have any soil disturbance as this would lead to possible wilting. Weeds within this area are likely to incur the most competition of all as they are so close to the crop plant's resources. Retardation of weeds in this area must rely on intelligent sensing and highly targeted energy inputs such as micro spraying or laser weeding.

Laser weeding holds great promise as it uses a highly mobile focused beam of infra red light to thermally disrupt cell membranes in the weed leaves and shoots. The beam can be controlled easily by computer and can significantly reduce the energy needed for thermal weed control (Griepentrog et al., 2006). Location of weed leaves can be achieved by machine vision (as above).

\subsubsection{Micro Spraying}

Micro spraying takes the concept of a spray boom down to the centimetre level (Søgaard et al., 2006). It applies highly targeted chemicals and can treat small areas by selectively switching the jets on and off. It is part of a larger system that can recognise individual weed plants and locate their leaves for treatment (see weed mapping).

Trials have shown that when herbicide is targeted in the right way at the right time, the usage can be drastically reduced. Tests were carried out by a human operator to identify and treat individual weed plants that resulted in reducing the application of glyphosphate from 720 grams per hectare down to about 1 gram per hectare for an infestation of 100 weeds per square meter and maintain acceptable efficacy (Graglia, 2004). If this same approach can be carried out by an autonomous micro sprayer then there will be significant economic and environmental advantages.

\subsubsection{Biodiversity}

Controlled biodiversity is a management strategy that allows non-competitive weeds to grow when they are at a distance from the crop. It allows other species, apart from the crop, to flourish and can be seen as beneficial to the environment by encouraging interdependent fauna and reducing the risk of erosion.

B.S. Blackmore, H. Griepentrog, S. Fountas, and T. Gemtos. "A Specification for an Autonomous Crop Production Mechanization System”. Agricultural Engineering International: the CIGR Ejournal. Manuscript PM 06 032. Vol. IX. September, 2007. 


\subsubsection{Robotic Gantry}

Traditional or macro spraying can be very efficient, especially when covering large areas. Most equipment manufacturers are developing larger machines, with 42 meter booms currently under development (pers. com. Hardi International). When mounting booms this big, they have inherent stability problems as the tractor has a relatively small wheelbase and they tend to oscillate. One method to improve stability would be to mount a spray boom between two unmanned robots that travelled in adjacent tramlines. This robotic gantry could apply both liquid sprays and fertiliser and be able to regulate itself according to current weather conditions. If it became too windy then the gantry could just stop and wait until conditions improved. Variable rate, patch spraying, minimising skips and overlaps could all be built into the original design specifications by controlling individual nozzles. Turning on the headland would be different, as it would not include rotation - just translation, as the robots could turn but the boom remains parallel to its working direction. Sensing systems could be mounted on a trolley that could move along the spray boom as in the crop scouting scenario.

\subsection{Mechanisation for Crop Care}

\subsubsection{Crop Scouting}

A high clearance platform is useful to carry instruments above the crop canopy and utilise GPS. Most crop sensing systems are more effective when positioned directly above the crop canopy (Bak and Jakobsen, 2003).

Smaller sub canopy machines have been developed in student competitions (www.fieldrobot.com) but are likely to be limited in their use as they will be severely restricted in size and hence constrained by the storage of energy in such a small volume.

\subsubsection{Micro Spraying}

Within the close-to-crop area, great care must be taken not to damage the crop nor disturb the soil. The use of a micro spray that delivers very small amounts directly on to the weed leaf has been fitted to the crop scouting robot described above. Machine vision can be used to identify the position of an individual weed plant and a set of nozzles mounted close together can squirt a herbicide on to the weed. Tests have shown that splashing can be reduced when a gel is used as a carrier rather than water (Søgaard and Lund, 2005).

B.S. Blackmore, H. Griepentrog, S. Fountas, and T. Gemtos. "A Specification for an Autonomous Crop Production Mechanization System”. Agricultural Engineering International: the CIGR Ejournal. Manuscript PM 06 032. Vol. IX. September, 2007. 


\subsubsection{Robotic Irrigation}

A robotic irrigator in the form of a mechatronic sprinkler (to simulate a travelling rain gun) was developed to apply variable rates of water and chemigation to predefined areas. The trajectory and sector angles of the jet were controlled by stepper motors and could be adjusted according to the current weather conditions and the desired pattern by a small computer. As the airborne water can be blown down wind, the instantaneous jet angles can be adjusted to compensate by measuring the wind speed and direction (Turker et al., 1998). This system could not only apply more spatially precise application of water but can also irrigate into field corners without applying water outside the boundary.

\section{HARVESTING}

\subsection{Concepts for Harvesting}

\subsubsection{Selective Harvesting}

At present, crops are usually harvested when the average of the whole field is ready as this simplifies the harvest process. Selective harvesting involves the concept of only harvesting those parts of the crop that meet certain quantity or quality thresholds. It can be considered to be a type of pre sorting based on sensory perception. Examples are to only harvest barley below a fixed protein content or combine grain that is dry enough (and leave the rest to dry out) or to select and harvest fruits and vegetables that meet a size criteria. As these criteria often attract quality premiums, increased economic returns could justify the additional sensing. Benefits of multiplepass system than a single-pass for corn harvested for biomass has been reported by Shineers et al. (2003), as well as the advantages for selective harvesting of asparagus (Cembali et al., 2005) and dates in Iran (Abounajmi, 2004).

To be able to carry out selective harvesting effectively, two criteria are have to be met; the ability to sense the quality factor before harvest and the ability to harvest the product of interest without damaging the remaining crop. Most agricultural equipment is getting bigger and hence not suited for this approach. Smaller more versatile selective harvesting equipment is needed. Either the crop can be surveyed before harvest so that the information needed about where the crop of interest is located, or that the harvester may have sensors mounted that can ascertain the crop condition. The selective harvester can then harvest that crop that is ready, while leaving the rest to mature, dry, or ripen etc.

B.S. Blackmore, H. Griepentrog, S. Fountas, and T. Gemtos. "A Specification for an Autonomous Crop Production Mechanization System”. Agricultural Engineering International: the CIGR Ejournal. Manuscript PM 06 032. Vol. IX. September, 2007. 
Alternatively, small autonomous whole crop harvesters could be used to selectively gather the entire crop from a selected area and transport it to a stationary processing system that could clean, sort and maybe pack the produce. This is not a new idea, but updating a system that used stationary threshing machines from many years ago. Alternatively, a stripper header could be used to only gather the cereal heads and send them for threshing.

As selective harvesting only harvests products of desired quality the harvesting process will be phased over a longer periods of time, negating the need for large equipment. As the products are already graded or sorted, it also adds value to the products before they leave the farm.

\subsubsection{Static Threshing and Processing}

Instead of a harvester carrying around a complete threshing system, as is often done at present, the collection and threshing or separating the products from the crop can be done by two different systems. The mobile harvester could selectively collect those parts of the crop that are of interest, while static machinery could then grade or process the crop into the desired products. This process could be extended to include packing and boxing where applicable, thus adding more value to the farm products.

\subsubsection{Transportation}

An autonomous transporters would be able to rendezvous with both the harvester and the unloading apparatus back at the farm or storage area (Morimoto et al., 2005). It should be able to accept field produce from the harvester without stopping and unload at a pre designated point for further transport, processing or storage. Multiple vehicles could ferry products around the farm. If the overall load per vehicle is kept low then issues of compaction do not arise. Conversely, compaction during harvest is not always a problem as harvest often occurs during dry periods when the soil is at its strongest.

\subsection{Mechanisation for Harvesting}

Many robotic pickers have been developed for high value row crops - especially in Japan (Kondo et al., 2006). These usually use machine vision to sense the colour, shape and location of the product before directing a robotic arm with a specialised end-effector to pick the product.

Mechanisation for harvesting broad acre crops are more difficult to design using the selective harvesting concepts as they often rely on clearing the crop in front of the harvester. Selectively harvesting areas from a standing crop would require a predefined route plan to minimise the harvest of areas not meeting the selective harvesting requirements.

B.S. Blackmore, H. Griepentrog, S. Fountas, and T. Gemtos. "A Specification for an Autonomous Crop Production Mechanization System”. Agricultural Engineering International: the CIGR Ejournal. Manuscript PM 06 032. Vol. IX. September, 2007. 
Existing stripper head technology goes some way to reducing the energy needed and reduces the requirement to transport a complex threshing mechanism. It could be easily adapted to work with a new autonomous harvester that could be used with stationary processing.

\section{CONCLUSIONS}

In conclusion, it can be seen that there are many factors that need to be taken into account when specifying a new mechanisation system of the proposed type. Some of the requirements have been presented here but there are many more that need to be included. Most mechanical, hydraulic and electronic technologies are already sufficient to exploit these concepts. It is inevitable that machines will become smarter and full autonomy is only a matter of time but to achieve this, and the associated benefits, we need to clearly identify how smart they need to be and define the appropriate behaviours.

\section{REFERENCES}

Abounajmi, M., 2004. Mechanization of Dates Fruit Harvesting. ASAE Paper No. 041028. St. Joseph Mich.: ASAE.

Bak, T. and H. Jacobsen. 2003. Agricultural Robotic Platform with Four Wheel Steering for Weed Detection. Biosystems Engineering 87: 2125-136.

Birrell, S. J. and J. W. Hummel. 2001. Real-time multi ISFET/FIA soil analysis system with automatic sample extraction. Computers and Electronics in Agriculture 32(1): 45-67.

Blackmore, B. S., H. Have, and S. Fountas. 2001. A specification of behavioural requirements for an autonomous tractor (Keynote address). In Proc. 6th International Symposium on Fruit, Nut and Vegetable Production Engineering Conference, 11-19 Sept. 2001, eds. M. Zude, B. Herold, and M. Guyer, 25-36. Potsdam - Bornim, Germany: Institute für Agrartechnik Bornim.

Blackmore, S., H. Have and S. Fountas. 2002. Proposed system architecture to enable behavioural control of an autonomous tractor. In Proc. ASAE Conference on Automation Technology for Off-road Equipment, Chicago, USA, July 26-26, 2002.

Blackmore, B. S., S. Fountas, S. Vougioukas, L. Tang, C.G. Sørensen, and R. Jørgensen. 2004a. A method to define agricultural robot behaviours. In Proc. MECHROB: Mechatronics \&

B.S. Blackmore, H. Griepentrog, S. Fountas, and T. Gemtos. "A Specification for an Autonomous Crop Production Mechanization System”. Agricultural Engineering International: the CIGR Ejournal. Manuscript PM 06 032. Vol. IX. September, 2007. 
Robotics Conference, 13-15 Septemeber, 1197-1200, Aachen, Germany: IEEE Industrial Electronics Society and APS.

Blackmore, S., S. Fountas, L. Tang and H. Have. 2004b. Systems requirements for small autonomous agricultural vehicles. Agricultural Engineering International: the CIGR Ejournal. Manuscript PM 04 001. Vol. VI. July

Brooks, R. A. 1986. A robust layered control system for a mobile robot. Journal of Robotics and Automation RA-2: 14-23.

Brooks, R. 1999. Cambrian Intelligence: The early history of the new AI. The MIT Press, Cambridge, Massachusetts, 199 pp.

Cembali, T., J.R., Folwell, , T. Ball and D.D. Clary. 2005. Economic Comparison of Selective and Non-Selective Mechanical Harvesting of Asparagus. ASAE Paper No. 053003. St. Joseph Mich.: ASAE.

Chamen, W. C. T., D. Dowler, P.R. Leede, and D. J. Longstaff. 1994. Design, operation and performance of a gantry system: Experience in arable cropping. Journal of Agricultural Engineering Research 59: 145-60.

Chi, Y. T. and P. P. Ling. 2004. Fast Fruit identification for Robotic Tomato Picker. ASAE Paper No: 043083. St. Joseph Mich.: ASAE.

Christensen, L. K., S. K. Upadhyaya, B. Jahn, D. C. Slaughter, E. Tan, and D. Hills. 2005. Determining the influence of water deficiency on NPK stress discrimination in maize using spectral and spatial information. Precision Agriculture Journal 6: 539-550.

Fountas, S., D. Wulfsohn, S. Blackmore, H. L. Jacobsen and S.M., Pedersen. 2006. A model of decision making and information flows for information-intensive agriculture. Agricultural Systems 87, 192-210.

Godwin, R. J., R. Earl, J. C. Taylor, G. A. Wood, R. I. Bradley, J. P. Welsh, T. Richards, B. S. Blackmore, M. C. Carver, S. M. Knight and B. Welti. 2001. Precision Farming of cereal crops: A five-year experiment to develop management guidelines. Project report 264e, 328pp. London, UK: Home Grown Cereals Authority.

Graglia, E. 2004. Importance of herbicide concentration, number of droplets and droplet size on growth of Solanum nigrum L, using droplet application of Glyphosphate. XIIeme Colloque International sur la Biologie des Mauvaises Herbes.

Griepentrog, H. W., M. Nørremark, H. Nielsen, and B. S. Blackmore. 2005a. Seed Mapping of Sugar Beet. Precision Agriculture Journal 6: 2157-165.

B.S. Blackmore, H. Griepentrog, S. Fountas, and T. Gemtos. "A Specification for an Autonomous Crop Production Mechanization System”. Agricultural Engineering International: the CIGR Ejournal. Manuscript PM 06 032. Vol. IX. September, 2007. 
Griepentrog, H. W., P. T. Skou, J. F. Soriano and B. S. Blackmore. 2005b. Design of a seeder to achieve highly uniform sowing patterns. In Proc. 5th European conference on Precision Agriculture, ed. J. Stafford, 675-682, 8-11 June. Uppsala, Sweden: Wageningen Academic Publishers.

Griepentrog, H. W., M. Nørremark, J. Nielsen and J. F. Soriano. 2006. Close-to-crop thermal weed control using a CO2 laser. In Proc. Proceedings of CIGR World Congress, 3-7 September, Bonn Germany: EurAgEng, CIGR.

Hannan , W. M. and F. T. Burks. 2004. Current Developments in Automated Citrus Harvesting. ASAE Paper No. 043087. St. Joseph Mich.: ASAE.

Have, H., B.S. Blackmore, B. Keller, S. Fountas, H. Nielsen and F. Theilby. 2002. Autonomous weeder for Christmas tree plantations - A feasibility study. In Proc. EurAgEng02: European Conference of Agricultural Engineering, June 30-July 4, Budapest, Hungary, Paper No. 02AE-023: EurAgEng.

Hollingum, J., 1999. Robots in agriculture. Industrial Robot 26(6): 438-445.

Ieropoulos, I., J. Greenman, and C. Melhuish. 2003. Imitating metabolism: Energy autonomy in biologically inspired robots. In Proc. AISB '03 Second international symposium on imitation in animals and artifacts, 191-104. Aberystwyth, Wales, 7-11 April.

Kataoka, T., H. Okamoto and S. Hata. 2001. Automatic detecting system of apple harvest season for robotic apple harvesting. ASAE Paper No: 013132. St. Joseph Mich.: ASAE.

Kelly, I., O. Holland and C. Melhuish. 2000. SlugBot: A robotic predator in the natural world. Ib Proc. 5th International symposium on artificial life and robotics, 470-475. Oita, Japan, 26-28 January.

Kondo, N. and K. C. Ting. 1998. Robotics for Bioproduction Systems. St. Joseph: ASAE Publication.

Kondo, N., K. Ninomiya, S. Hayashi, T. Ohta and K. Kubota. 2005. A New Challenge of Robot for Harvesting Strawberry Grown on Table Top Culture. ASAE Paper No: 043083. St. Joseph Mich.: ASAE.

Kondo, N., M. Monta, and N. Noguchi. 2006. Agri-Robot (II) - Mechanisms and Practice. (In Japanese).

Morimoto, E., M. Suguri and M. Umeda. 2005. Vision-based naviagation suystem for autonomous transportation vehicle. Precision Agriculture 6: 239-254.

B.S. Blackmore, H. Griepentrog, S. Fountas, and T. Gemtos. "A Specification for an Autonomous Crop Production Mechanization System”. Agricultural Engineering International: the CIGR Ejournal. Manuscript PM 06 032. Vol. IX. September, 2007. 
Na, Y.-K. and S.-Y. Oh. 2003. Hybrid control for autonomous mobile robot navigation using neural network based bahaviour modules and environment classification. Autonomous Robots 15, 193-206.

Nørremark, M. and H. W. Griepentrog. 2004. Physical methods to control weeds within crop rows. In Proc. AgEng04, 12-16 September, Leuven, Belgium.

Pedersen, B. B. 2001. Weed density estimation from digital images in spring barley. MSc thesis. Taastup, Denmark: The Royal Veterinary and Agricultural University.

Pedersen, S. M., S. Fountas, H. Have and B.S. Blackmore. 2006. Agricultural robots - system analysis and economic feasibility. Precision Agriculture 7(4): 295-308.

Pilarski, T., M. Happold, H. Pangels, M. Ollis, K. Fitzpatrick and A. Stentz. 2002. The Demeter system for automated harvesting. Autonomous Robots 13(1): 9-20.

Shibusawa, S. 1996. PhytoTechnology - An introduction to the concept and topic of a new project. School of Bio-Applications and Systems Engineering, Tokyo University of Agriculture and Technology.

Shibusawa, S., I. M. Anom, H. Sata, A. Sasao, S. Hirako, A. Otomo and B. S. Blackmore 2000. On-line real-time soil spectrophotometer. In Proc. 5th International Conference on Precision Agriculture. eds. P. C. Robert, R. H. Rust, and W. E. Larson: ASA, CSSA, SSSA \& ASAE.

Shinners, J. K., N. B. Binversie and P. Savoie. 2003. Whole-plant corn harvesting for biomass: comparison of single-pass and multiple-pass harvest systems. ASAE Paper No: 036089. St. Joseph, Mich.: ASAE.

Søgaard, H. T. and T. Heisel. 2002. Weed classification by active shape models. In Proc AgEng 2002, International Conference on Agricultural Engineering, June 30-July 4, Budapest, Hungary.

Søgaard, H. T. and I. Lund. 2005. Investigation of the accuracy of a machine vision based robotic micro spray system. In Proc. 5th European conference on Precision Agriculture, 811 June., ed. J. Stafford, 613-619. Uppsala, Sweden: Wageningen Academic Publishers.

Søgaard, H.T., Lund, I. and E. Graglia. 2006. Real-time Application of Herbicides in Seed Lines by Computer Vision and Micro-Spray System. ASAE Paper No. 061118.

Tang, L., L. Tian, and B. L. Steward. 2000. Color image segmentation with genetic algorithm for in-field weed sensing. Transactions of the ASAE 43: 41019-1028.

B.S. Blackmore, H. Griepentrog, S. Fountas, and T. Gemtos. "A Specification for an Autonomous Crop Production Mechanization System”. Agricultural Engineering International: the CIGR Ejournal. Manuscript PM 06 032. Vol. IX. September, 2007. 
Tothill, I. E., 2001. Biosensors developments and potential applications in the agricultural diagnosis sector. Computers and Electronics in Agriculture, Volume 30 (1-3) 205-218.

Turing, A. 1950. Computing machniery and intelligence. Mind 59: 433-60.

Turker, U., B. S. Blackmore and E. K. Weatherhead. 1998. Development of a Robotic Sprinkler Head for Precision Irrigation. In Proc. 13th International Conference on Agricultural Engineering, 2-6 February, Rabat, Morocco: CIGR.

Yavuz, H., Bradshaw, A., 2002. A new conceptual approach to the design of hybrid control architecture for autonomous mobile robots. Journal of Intelligent and Robotic Systems 34, 126.

Waine, T. 1999. Non-Invasive Soil Property Measurement for Precision Farming. EngD. thesis. Silsoe, UK: Cranfield University at Silsoe.

Waine, T. W., B. S. Blackmore and R. J. Godwin. 2000. Mapping available water content and estimating soil textural class using electro-magnetic induction. In Proc. EurAgEng, Paper no. 00-SW-044.Warwick, UK: Silsoe Research Institute.

Wilson, J. N. 2000. Guidance of agricultural vehicles - a historical perspective. Computers and Electronics in Agriculture 25, 1-9.

B.S. Blackmore, H. Griepentrog, S. Fountas, and T. Gemtos. "A Specification for an Autonomous Crop Production Mechanization System”. Agricultural Engineering International: the CIGR Ejournal. Manuscript PM 06 032. Vol. IX. September, 2007. 